\title{
A Quantitative Genomic View of the Coronaviruses: SARS-COV2
}

\author{
Sk. Sarif Hassan ${ }^{\mathrm{a}, *}$, Ranjeet Kumar Rout ${ }^{\mathrm{b}}$, Vipul Sharma ${ }^{\mathrm{b}}$ \\ ${ }^{a}$ Dept. of Mathematics, Pingla Thana Mahavidyalaya, Paschim Medinipur-721140, India \\ ${ }^{b}$ Department of Computer Science $\mathcal{E}$ Engineering, National Institute of Technology, \\ Hazratbal, Srinagar, India
}

\begin{abstract}
In 2020, the pandemic caused by the Coronaviruses $(\mathrm{CoV})$ that are a large family of viruses that cause illness ranging from the common cold to more severe diseases such as Middle East Respiratory Syndrome (MERS-CoV) and Severe Acute Respiratory Syndrome (SARS-CoV2). The Coronavirus disease (COVID-19) is a new strain that was discovered in 2019 and has not been previously identified in humans. It is the high time to investigate the quantitative and/or qualitative genomic informations of the virus SARS-CoV2 in order to strengthen the healthcare facility to fight against this viral disease. In this article, a through quantitative understanding of the purine and pyrimidine spatial distribution/organization of all 89 complete sequences of SARS-CoV (available as on date in the NCBI virus database, is made using different parameters such as fractal dimension, Hurst exponent, Shannon entropy and $G C$ content of the nucleotide sequences of the genome of SARS-CoV2. Also a cluster among all the the SARS-CoV sequences of nucleotide have been made based on their phylogeny made through their closeness (Hamming distance) based on respective purine-pyrimidine distribution.
\end{abstract}

Keywords: Fractal Dimension, Shannon Entropy, Hurst Exponent, GC Content \& SARS-CoV2.

\footnotetext{
${ }^{*}$ Corresponding author

Email addresses: sarimif@gmail.com (Sk. Sarif Hassan ), ranjeetkumarrout@nitsri.net (Ranjeet Kumar Rout), vipul_1phd17@nitsri.net (Vipul Sharma)
} 


\section{Introduction}

The Coronavirus disease (COVID-19) is caused by SARS-COV2 and represents the causative agent of a potentially fatal disease that is of great global public health concern [1], 2]. Based on the large number of infected people that

5 were exposed to the wet animal market in Wuhan City, China, it is suggested that this is likely the zoonotic origin of COVID-19 [3, 4, 5]. Person-to-person transmission of COVID-19 infection led to the isolation of patients that were subsequently administered a variety of treatments [6, 7]. As of 11 February 2020, data from the World Health Organization (WHO) have shown that more than 43000 confirmed cases have been identified in 28 countries/regions, with $\geq 99 \%$ of cases being detected in China 8 . On 30 January 2020, the WHO declared COVID-19 as the sixth public health emergency of international concern [9]. SARS-CoV2 is closely related to two bat-derived severe acute respiratory syndrome-like coronaviruses, bat-SL-CoVZC45 and bat-SL-CoVZXC21 15 [10]. On 11 February 2020, the WHO formally named the disease triggered by $2019-n C o V$ as coronavirus disease 2019 (COVID-19). Also on that very day, the coronavirus study group of the International Committee on Taxonomy of Viruses named $2019-n C o V$ as severe acute respiratory syndrome coronavirus 2 (SARS-CoV2) [11. Complete genomic sequences have been released by the ${ }_{20} \mathrm{NCBI}$ in the last few weeks to understand the evolutionary origin and molecular characteristics of this virus [12]. Ceraolo and Giorgi [13] have confirmed the high sequence similarity (>99\%) between all sequenced $2019 \mathrm{CoVs}$ genomes available, with the closest $\mathrm{BCoV}$ sequence sharing $96.2 \%$ sequence identity, confirming the notion of a zoonotic origin of $2019-n C o V$. Coronaviruses are enveloped RNA

25 viruses that are distributed broadly among humans, other mammals, and birds and that cause respiratory, enteric, hepatic, and neurologic diseases [10, 14, 15].

As on date 15th March, 2020, there are 89 nucleotide sequences of SARSCoV2 available in the NCBI virus database [16, 17. All these sequences are 
nearly about length 29 thousand and each of them are composed of four nucleotide bases viz. $A, T, C$ and $G$. Importantly, they all are different from each other by means of spatial organizations of the nucleotide bases.

In this study, our aim is to attempt to discover the signatory imprint of this spatial organizations of the SARS-CoV2. The spatial distribution of the purine and pyrimidine bases over the nucleotide sequences of the SARS-CoV2 are being fetched out through some quantitative parameters such as fractal dimension, Hurst exponent and Shannon entropy. In addition, also density of each of the bases are also seen and density of GC content is also determined in order to understand the stability of the DNAs.

This discovery would aid in the diagnosis of SARS-CoV2 virus infection in humans and potential animal hosts (using polymerase chain reaction and immunological tests), in the development of antivirals (including neutralizing

45 antibodies), and in the identification of putative epitopes for vaccine development.

\subsection{Database used and Specifications}

In this work we have taken all nucleotide sequences from the NCBI Virus Database (https : //www.ncbi.nlm.nih.gov/labs/virus/vssi/) for experimental results and discussion purpose. This dataset contains 89 complete SARS-CoV2 nucleotide sequences as on date 15th March, 2020. We have transformed each DNA sequence to a binary sequence of $0^{\prime} s$ and $1^{\prime} s$ which is defined in equation 1 Here purines and pyrimidines nucleotide bases are represented as "1" and "0" respectively.

$$
\begin{aligned}
& A / G \rightarrow 0 \\
& T / C \rightarrow 1
\end{aligned}
$$

Equation(1) represents purine and pyrimidine nucleotide bases which are encoded as 1 and 0 respectively into the transformed binary sequence. 
Before we proceed further, we have named all the 89 complete SARS-CoV2 nucleotide sequences based on their accession ID as listed below in the Table 1. 
Table 1: Naming the Nucleotide sequences of SARS-CoV2.

\begin{tabular}{|c|c|c|c|c|c|}
\hline Sequence & Accession ID & Sequence & Accession ID & Sequence & Accession ID \\
\hline S1 & NC_045512 & S31 & MT121215 & $\mathrm{S} 61$ & MT039873 \\
\hline $\mathrm{S} 2$ & MT188341 & S32 & MT159719 & S62 & MT039887 \\
\hline S3 & MT188339 & S33 & MT159720 & S63 & МТ039890 \\
\hline S4 & MT188340 & S34 & MT159709 & S64 & МT027063 \\
\hline S5 & MT184910 & S35 & MT159718 & S65 & МТ027064 \\
\hline S6 & MT184908 & S36 & МТ012098 & S66 & MT027062 \\
\hline S7 & MT184909 & S37 & МT050493 & S67 & МT019529 \\
\hline S8 & MT184911 & S38 & MT152824 & S68 & МТ020880 \\
\hline S9 & MT184913 & S39 & MT135044 & S69 & МТ019530 \\
\hline S10 & MT184912 & S40 & MT135042 & S70 & MT019532 \\
\hline S11 & MT184907 & S41 & MT135043 & S71 & MT019533 \\
\hline S12 & MT163716 & S42 & MT135041 & S72 & МT020881 \\
\hline S13 & MT163719 & S43 & MT126808 & S73 & MT019531 \\
\hline S14 & MT163717 & S44 & MT123291 & S74 & MT007544 \\
\hline S15 & MT163718 & S45 & MT123290 & S75 & MN996527 \\
\hline S16 & MT159711 & S46 & MT123293 & S76 & MN996531 \\
\hline S17 & MT159710 & S47 & MT123292 & S77 & MN996528 \\
\hline S18 & MT159708 & S48 & MT118835 & S78 & MN996530 \\
\hline S19 & MT159712 & S49 & MT106054 & S79 & MN996529 \\
\hline S20 & MT159716 & S50 & MT106053 & $\mathrm{S} 80$ & MN988668 \\
\hline $\mathrm{S} 21$ & MT159707 & S51 & MT106052 & S 81 & MN997409 \\
\hline $\mathrm{S} 22$ & MT159715 & S52 & MT093571 & S82 & MN994467 \\
\hline $\mathrm{S} 23$ & MT159721 & S53 & МТ093631 & S83 & MN988669 \\
\hline S24 & MT159717 & S54 & МТ072688 & S84 & MN994468 \\
\hline S25 & MT159722 & S55 & MT066175 & S85 & MN988713 \\
\hline S26 & MT159714 & S56 & MT066176 & S86 & MN975262 \\
\hline S27 & MT159713 & S57 & MT044257 & S87 & MN938384 \\
\hline $\mathrm{S} 28$ & MT159706 & S58 & МТ049951 & S 88 & MN985325 \\
\hline $\mathrm{S} 29$ & MT066156 & S59 & MT044258 & S89 & MN908947 \\
\hline S30 & MT159705 & $\mathrm{S} 60$ & МТ039888 & & \\
\hline
\end{tabular}


Viruses of the family Coronaviridae possess a single-strand, positive-sense

60 complete 89 sequences is varying from 29783 to 29981 . So the range is $198 \mathrm{bp}$ long. The smallest complete SARS-CoV sequence is S2 of length 29783 and the largest one is S47 having length 29981. There are two sequences S23 and S28 having length 29867 and few others having same lengths. There are 39 sequences having exactly same length which is 29882 . Also there are 11 sequences having length 29903.

\section{Proposed Methods}

In this section, four different quantitative parameters have been defined to characterize the spatial distribution of the SARS-CoV2 sequences. Based on quantitative parameters (Shannon Entropy, Fractal Dimension, Hurst Exponent, distribution of purines- pyrimidines) ten different clusters have be generated. Following we present the methods in brief.

\subsection{Fractal Dimension of Indicator Matrices}

Let $D=\{0,1\}$ be the set of two symbols characterizing the purine and 75 pyrimidine bases of a nucleotide sequence and $S(l)$ be a binary sequence corresponding to a nucleotide sequence with the repetition of two characters from $D$ of length $l$. Here, we convert each of the binary sequences into indicator matrices [18, 19, 20, 21]. In literature [22] there are several methods to find out the self organising structure of DNA sequences through indicator matrix. Then the indicator function for each sequence is defined as shown in equation 2

$$
\vartheta:\{0,1\} \times\{0,1\} \rightarrow\{0,1\}
$$

such that the indicator matrix:

$$
\vartheta_{h k}=\vartheta(x, y)=\left\{\begin{array}{l}
1, \text { if } x=y \\
0, \text { if } x \neq y
\end{array} \quad \text { where } x, y \in\{0,1\}\right.
$$


Here $\vartheta_{h k}$ is a matrix with the distribution 0 and 1. A binary image can be obtained from the matrix through which we can visualise correlation between purines and pyrimidines and auto-correlation for the same sequence. It can be well understood by assigning a black dot to 1 and a white dot to 0 . From the indicator matrix we can visualise the fractal like distribution of $0^{\prime} s$ and $1^{\prime} s$ (purines and pyrimidines). The fractal dimension of the indicator matrix can calculated as the average number of $\sigma(p)$ of 1 , which can be taken from 90 $P \times P$ indicator matrix with $p \times p$ randomly. Using $\sigma(p)$, the fractal dimension is defined in equation 3

$$
D=-\frac{1}{P} \sum_{n=2}^{P} \frac{\log \sigma(p)}{\log p}
$$

The self-organization of the purine and pyrimidine bases for all the SARSCoV2 sequences can be obtained through the fractal dimension of the indicator matrix.

\subsection{Hurst Exponent}

The Hurst Exponent (HE) is used for time series analysis to interpret the autocorrelation [23, 24]. The value of $\mathrm{HE}$ is in between 0 to 1 . The HE value $0<H E<0.5$ and $0.5<H E<1$ designates negative and positive autocorrelation of a time series respectively and 0.5 denotes a absolute randomness of a time series which indicates the equally likely value from a particular value either by increasing or by decreasing. The $\mathrm{H} E$ of a binary sequence $s_{n}$ is defined as

$$
\left(\frac{n}{2}\right)^{H E}=\frac{X(n)}{Y(n)}
$$

where

$$
Y(n)=\sqrt{\frac{1}{n} \sum_{i=1}^{n}\left(s_{i}-m\right)}
$$

and $X(n)=\max T(i, n)-\min T(i, n)$, where

$$
T(i)=\sum_{j=1}^{n}\left(s_{i}-t\right)
$$


and

$$
t=\sqrt{\frac{1}{n} \sum_{i=1}^{n} s_{i}}
$$

The auto correlation of purine-pyrimidine bases for all the SARS-CoV2 sequences is obtained through the Hurst exponent. temperature of the DNA double helix using spectrophotometry.

In addition to the GC content, the density of the nucleotides $A, T, C$ and $G$ also separately are obtained in the present study [31, 32]. 


\section{Results and Illustrations}

It is well understood from their very frequency of number of nucleotides usages that the SARS-CoV2 sequences are not randomly chosen. So we explicitly trying to get the spatial distribution of the purine and pyrimidine organizations among the SARS-CoV2 sequences through the parameters as defined in the previous section. In addition to the investigation of the purine-pyrimidine distribution, we wish to explore the density of each of the nucleotides as well as $G C$ content which has a significant role in stability.

\subsection{Classification Based on Fractal dimension of Indicator Matrices}

For each binary sequence (purine and pyrimidine) of SARS-CoV2, the fractal dimension (using Equation (3)) is calculated. Based on the fractal dimension, we have made classifications (clusters) for all the the SARS-CoV2 sequences. There are three distinct fractal dimensions $(0.3,0.4755$ and 0.6$)$ have been obtained and consequently only three clusters of the sequences are turned up. The following Table 2 demonstrate the sequences and their corresponding FDs. 
Table 2: Sequences and their corresponding FDs

\begin{tabular}{llllllllll}
\hline Seq & FD & Seq & FD & Seq & FD & Seq & FD & Seq & FD \\
\hline S47 & 0.300 & $\mathrm{~S} 7$ & 0.6 & $\mathrm{~S} 26$ & 0.6 & $\mathrm{~S} 45$ & 0.6 & $\mathrm{~S} 72$ & 0.6 \\
$\mathrm{~S} 13$ & 0.300 & $\mathrm{~S} 8$ & 0.6 & $\mathrm{~S} 27$ & 0.6 & $\mathrm{~S} 46$ & 0.6 & $\mathrm{~S} 73$ & 0.6 \\
$\mathrm{~S} 28$ & 0.300 & $\mathrm{~S} 9$ & 0.6 & $\mathrm{~S} 29$ & 0.6 & $\mathrm{~S} 52$ & 0.6 & $\mathrm{~S} 74$ & 0.6 \\
\hline $\mathrm{S} 79$ & 0.300 & $\mathrm{~S} 10$ & 0.6 & $\mathrm{~S} 30$ & 0.6 & $\mathrm{~S} 57$ & 0.6 & $\mathrm{~S} 75$ & 0.6 \\
$\mathrm{~S} 48$ & 0.475 & $\mathrm{~S} 11$ & 0.6 & $\mathrm{~S} 31$ & 0.6 & $\mathrm{~S} 58$ & 0.6 & $\mathrm{~S} 76$ & 0.6 \\
$\mathrm{~S} 49$ & 0.475 & $\mathrm{~S} 12$ & 0.6 & $\mathrm{~S} 32$ & 0.6 & $\mathrm{~S} 59$ & 0.6 & $\mathrm{~S} 77$ & 0.6 \\
\hline $\mathrm{S} 50$ & 0.475 & $\mathrm{~S} 14$ & 0.6 & $\mathrm{~S} 33$ & 0.6 & $\mathrm{~S} 60$ & 0.6 & $\mathrm{~S} 78$ & 0.6 \\
$\mathrm{~S} 51$ & 0.475 & $\mathrm{~S} 15$ & 0.6 & $\mathrm{~S} 34$ & 0.6 & $\mathrm{~S} 61$ & 0.6 & $\mathrm{~S} 80$ & 0.6 \\
$\mathrm{~S} 53$ & 0.475 & $\mathrm{~S} 16$ & 0.6 & $\mathrm{~S} 35$ & 0.6 & $\mathrm{~S} 62$ & 0.6 & $\mathrm{~S} 81$ & 0.6 \\
\hline $\mathrm{S} 54$ & 0.475 & $\mathrm{~S} 17$ & 0.6 & $\mathrm{~S} 36$ & 0.6 & $\mathrm{~S} 63$ & 0.6 & $\mathrm{~S} 82$ & 0.6 \\
$\mathrm{~S} 55$ & 0.475 & $\mathrm{~S} 18$ & 0.6 & $\mathrm{~S} 37$ & 0.6 & $\mathrm{~S} 64$ & 0.6 & $\mathrm{~S} 83$ & 0.6 \\
$\mathrm{~S} 56$ & 0.475 & $\mathrm{~S} 19$ & 0.6 & $\mathrm{~S} 38$ & 0.6 & $\mathrm{~S} 65$ & 0.6 & $\mathrm{~S} 84$ & 0.6 \\
\hline $\mathrm{S} 1$ & 0.600 & $\mathrm{~S} 20$ & 0.6 & $\mathrm{~S} 39$ & 0.6 & $\mathrm{~S} 66$ & 0.6 & $\mathrm{~S} 85$ & 0.6 \\
$\mathrm{~S} 2$ & 0.600 & $\mathrm{~S} 21$ & 0.6 & $\mathrm{~S} 40$ & 0.6 & $\mathrm{~S} 67$ & 0.6 & $\mathrm{~S} 86$ & 0.6 \\
$\mathrm{~S} 3$ & 0.600 & $\mathrm{~S} 22$ & 0.6 & $\mathrm{~S} 41$ & 0.6 & $\mathrm{~S} 68$ & 0.6 & $\mathrm{~S} 87$ & 0.6 \\
\hline $\mathrm{S} 4$ & 0.600 & $\mathrm{~S} 23$ & 0.6 & $\mathrm{~S} 42$ & 0.6 & $\mathrm{~S} 69$ & 0.6 & $\mathrm{~S} 88$ & 0.6 \\
$\mathrm{~S} 5$ & 0.600 & $\mathrm{~S} 24$ & 0.6 & $\mathrm{~S} 43$ & 0.6 & $\mathrm{~S} 70$ & 0.6 & $\mathrm{~S} 89$ & 0.6 \\
$\mathrm{~S} 6$ & 0.600 & $\mathrm{~S} 25$ & 0.6 & $\mathrm{~S} 44$ & 0.6 & $\mathrm{~S} 71$ & 0.6 & & \\
\hline
\end{tabular}

The plot of the FD and corresponding histogram are figured in the Fig. 1.
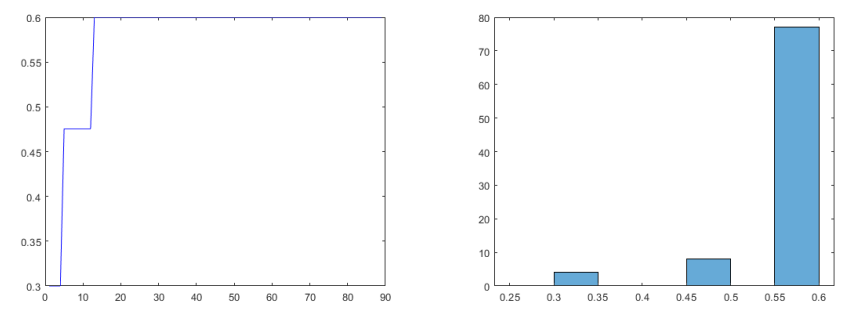

Figure 1: Plot of the Fractal dimension (FD) and corresponding histogram of all the purinepyrimidine binary sequences corresponding to SARS-CoV2 sequences. 
The dimension of each of indicator matrix is above $29000 \times 29000$ and consequently we fail to demonstrate image of the indicator matrix here. The sequences S47, S13, S28 and S79 have the FD 0.3 which depicts that the amount of fractality (a kind of non-linearity) is small and so the purine and pyrimidine organization is rather well-organized and closely affine-type. There are eight sequences S48, S49, S50, S51, S53, S54, S55 and S56 having FD 0.4755 and FD of rest all the sequences of purine and pyrimidine of SARS-CoV2 have been found as 0.6 which is close to the FD of cantor set, which is coincidentally significant [33, 34].

\subsection{Classification Based on Hurst exponent}

For each of the binary sequences of SARS-CoV2, the Hurst exponent (HE) (using Equation (4)) is determined and then ten clusters are formed using kmeans clustering technique for all the sequences. The Hurst exponents and the histograms of all the SARS-CoV2 sequences are plotted in the Fig. 2.

155 It has been observed that the $\mathrm{HE}$ is confined in the interval $(0.643,0.655)$ of length 0.0123. This suggests that spatial distribution of the purine and pyrimidine bases of all the SARS-CoV2 sequence is positively autocorrelated. It is noted that there is a sequence S1 having HE 0.712 which can be seen the following Table 3 . This sequence S1 (accession ID: $N C_{0} 4551$ ) has highest HE and clearly this sequence is having a significantly different spatial organization of purine and pyrimidine bases. The length of the sequence S1 is 29903. It is worth mentioning that there are other ten sequences (S1, S13, S14, S15, S39, S40, S41, S42, S57, S60 and S89) having same length 29903 but their HE is significantly differed from the HE of the sequence S1. 

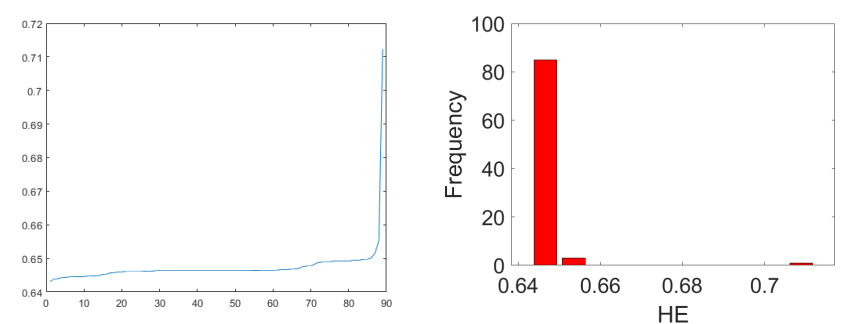

Figure 2: Plot of the Hurst exponent (HE) and corresponding histogram of all the purinepyrimidine binary sequences corresponding to SARS-CoV2 sequences.

Based on the HE obtained from the binary sequences of SARS-CoV2, ten clusters have been formed. The clusters are formed using k-means clustering. The cluster-1 contains 41 sequences (S81, S82, S62, S7, S11, S16, S17, S18, S19, S20, S24, S25, S26, S27, S29, S31, S32, S34, S48, S49, S50, S51, S64, S65, S66, S72, S73, S87, S8, S23, S9, S10, S83, S85, S44, S70, S80, S58, S59, S53, S45) having centre at 0.6464 . The cluster-2 contains 11 sequences (S39, S40, S41, S60, S74, S13, S14, S89, S57, S12, S3) having centre at 0.6494. The cluster 3 and 4 contain only one sequence each viz. S1, S47 respectively centres at $0.7125,0.6431$ respectively. The cluster-5 contains 11 sequences (S37, S77, S55, S56, S86, S61, S54, S46, S52, S6, S36) having centre at 0.6448. The sequence $175 \mathrm{~S} 30$ belongs to the cluster $\mathrm{S} 6$ whose centre is at 0.6554 . The sequences ( $\mathrm{S} 68, \mathrm{~S} 78$, $\mathrm{S} 88, \mathrm{~S} 71, \mathrm{~S} 67, \mathrm{~S} 42, \mathrm{~S} 15, \mathrm{~S} 69)$ are contained in the cluster-7 whose centre is at 0.6483. The cluster-8 contains sequences (S43, S63, S2, S5, S21, S22, S33, S35, $\mathrm{S} 38, \mathrm{~S} 84)$ whose center is at 0.6460 . The sequence $\mathrm{S} 4$ belongs to the cluster-9 whose centre is at 0.6516. The cluster 10 contains four sequences S79, S75, S76, S28 whose centre is at 0.6441. It is noted that the sequences S55 ands S66 have exactly same HE 0.6445500767 , which confirms their identical long-range correlation though the length of these two sequence (S55 is of length 29870 and S66 is of length 29872) is differed by $2 \mathrm{bp}$. Also it is seen that the sequences S21, S22, S33, S35 belonging to the cluster-8 have same HE 0.6460659477. For all the sequences S81, S82, S62, S7, S11, S16, S17, S18, S19, S20, S24, S25, S26, S27, S29, S31, S32, S34, S48, S49, S50, S51, S64, S65, S66, S72, S73 and 
S87 belonging to the cluster-1 have the HE 0.6463681216. In the same cluster-1, there are three sequences S9, S10, S83 having the same HE 0.6464832466. There are four sequences S39, S40, S41 and S60 which are contained in the cluster-2, having same HE 0.6491763266.

\subsection{Classification Based on Shannon Entropy}

For all the 89 binary sequences (purine-pyrimidine) of SARS-CoV2, the Shannon entropy (SE) are determined and then ten different clusters are formed based on SE obtained for all the sequences. The Shannon entropy and the histograms of all the SARS-CoV2 sequences are plotted in the Fig. 3.
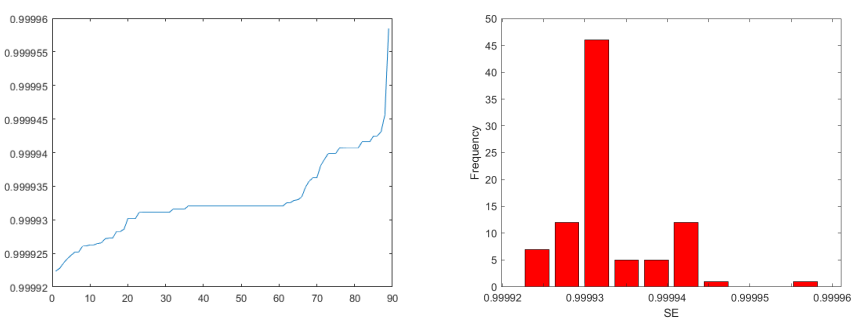

Figure 3: Plot of the Shannon entropy (SE) and corresponding histogram of all the purinepyrimidine binary sequences corresponding to SARS-CoV2 sequences.

It is obtained that the $\mathrm{SE}$ is ranging from 0.9999 to 1, i.e. the length of the range is too small. The SE is precisely same for all the sequences which is 0.9999 except one sequence S30 which is of length 29945. This confirms that the amount of uncertainly is at maximum and the probability of occurrence of purine and pyrimidine bases across the sequence S30 is 0.5. Although the sequence is not randomly composed (positively autocorrelated with HE 0.65538) of nucleotide bases, the purine and pyrimidine bases are composed with equal probability. 
Table 3: Hurst exponent of all the 89 purine-pyrimidine binary sequences corresponding to SARS-CoV2 sequences

\begin{tabular}{|c|c|c|c|c|c|}
\hline Sequence & HE & Sequence & HE & Sequence & HE \\
\hline $\mathrm{S} 47$ & 0.6430890415 & S11 & 0.6463681216 & $\mathrm{~S} 44$ & 0.6465117331 \\
\hline S79 & 0.6438083222 & S16 & 0.6463681216 & $\mathrm{~S} 70$ & 0.6466330524 \\
\hline S75 & 0.6439455807 & $\mathrm{~S} 17$ & 0.6463681216 & S80 & 0.6466330524 \\
\hline S76 & 0.644253158 & $\mathrm{~S} 18$ & 0.6463681216 & $\mathrm{~S} 58$ & 0.6466886489 \\
\hline $\mathrm{S} 28$ & 0.6443251468 & S19 & 0.6463681216 & S59 & 0.6467842124 \\
\hline S37 & 0.6444723241 & $\mathrm{~S} 20$ & 0.6463681216 & $\mathrm{~S} 53$ & 0.6468519632 \\
\hline S77 & 0.644522348 & $\mathrm{~S} 24$ & 0.6463681216 & $\mathrm{~S} 45$ & 0.6470843102 \\
\hline $\mathrm{S} 55$ & 0.6445500767 & $\mathrm{~S} 25$ & 0.6463681216 & S68 & 0.6475613391 \\
\hline S56 & 0.6445500767 & $\mathrm{~S} 26$ & 0.6463681216 & S78 & 0.6477094551 \\
\hline S86 & 0.6445721887 & $\mathrm{~S} 27$ & 0.6463681216 & $\mathrm{~S} 88$ & 0.6477094551 \\
\hline S61 & 0.6447294561 & $\mathrm{~S} 29$ & 0.6463681216 & S71 & 0.6483049547 \\
\hline $\mathrm{S} 54$ & 0.6447448006 & S31 & 0.6463681216 & S67 & 0.6487736204 \\
\hline S46 & 0.6447796066 & $\mathrm{~S} 32$ & 0.6463681216 & $\mathrm{~S} 42$ & 0.6488825729 \\
\hline $\mathrm{S} 52$ & 0.6448639682 & $\mathrm{~S} 34$ & 0.6463681216 & $\mathrm{~S} 15$ & 0.6488825729 \\
\hline S6 & 0.6452720329 & $\mathrm{~S} 48$ & 0.6463681216 & S69 & 0.6488862311 \\
\hline S36 & 0.6453293176 & S49 & 0.6463681216 & S39 & 0.6491763266 \\
\hline $\mathrm{S} 43$ & 0.6456954376 & $\mathrm{~S} 50$ & 0.6463681216 & $\mathrm{~S} 40$ & 0.6491763266 \\
\hline S63 & 0.6457628936 & $\mathrm{~S} 51$ & 0.6463681216 & S41 & 0.6491763266 \\
\hline $\mathrm{S} 2$ & 0.6459898777 & S64 & 0.6463681216 & $\mathrm{~S} 60$ & 0.6491763266 \\
\hline S5 & 0.6459943594 & S65 & 0.6463681216 & S74 & 0.6491856177 \\
\hline $\mathrm{S} 21$ & 0.6460659477 & S66 & 0.6463681216 & $\mathrm{~S} 13$ & 0.6494006145 \\
\hline $\mathrm{S} 22$ & 0.6460659477 & $\mathrm{~S} 72$ & 0.6463681216 & S14 & 0.6494692533 \\
\hline S33 & 0.6460659477 & S73 & 0.6463681216 & S89 & 0.6494692533 \\
\hline S35 & 0.6460659477 & $\mathrm{~S} 87$ & 0.6463681216 & $\mathrm{~S} 57$ & 0.6497613576 \\
\hline S38 & 0.6460690307 & S8 & 0.6464119458 & $\mathrm{~S} 12$ & 0.6497671065 \\
\hline S84 & 0.6461814077 & $\mathrm{~S} 23$ & 0.6464158218 & $\mathrm{~S} 3$ & 0.6501090217 \\
\hline S81 & 0.6462179229 & S9 & 0.6464832466 & $\mathrm{~S} 4$ & 0.651582672 \\
\hline S82 & 0.6462179229 & S10 & 0.6464832466 & S30 & 0.6553858343 \\
\hline S62 & 0.6463189347 & $\mathrm{~S} 83$ & 0.6464832466 & $\mathrm{~S} 1$ & 0.7124517615 \\
\hline S7 & 0.6463681216 & $\mathrm{~S} 85$ & 0.6464832466 & & \\
\hline
\end{tabular}


Table 4: Shannon entropy (SE) of all the purine-pyrimidine binary sequences corresponding to SARS-CoV2 sequences.

\begin{tabular}{|c|c|c|c|c|c|}
\hline Sequence & $\mathrm{SE}$ & Sequence & SE & Sequence & $\mathrm{SE}$ \\
\hline S47 & 0.9999223787 & $\mathrm{~S} 85$ & 0.9999311193 & S87 & 0.9999320596 \\
\hline $\mathrm{S} 28$ & 0.9999227878 & S81 & 0.9999315857 & S62 & 0.9999325138 \\
\hline S79 & 0.9999235693 & S82 & 0.9999315857 & S44 & 0.999932568 \\
\hline $\mathrm{S} 75$ & 0.9999242037 & S70 & 0.9999315948 & $\mathrm{~S} 58$ & 0.9999328857 \\
\hline S77 & 0.9999247235 & $\mathrm{~S} 80$ & 0.9999315948 & $\mathrm{~S} 45$ & 0.9999329935 \\
\hline $\mathrm{S} 37$ & 0.9999252013 & $\mathrm{~S} 7$ & 0.9999320596 & $\mathrm{~S} 23$ & 0.9999333912 \\
\hline $\mathrm{S} 76$ & 0.9999252013 & $\mathrm{~S} 11$ & 0.9999320596 & $\mathrm{~S} 53$ & 0.9999348593 \\
\hline $\mathrm{S} 46$ & 0.9999260645 & S16 & 0.9999320596 & S68 & 0.9999357908 \\
\hline S86 & 0.9999261031 & $\mathrm{~S} 17$ & 0.9999320596 & S78 & 0.9999362496 \\
\hline $\mathrm{S} 55$ & 0.9999262613 & $\mathrm{~S} 18$ & 0.9999320596 & S88 & 0.9999362496 \\
\hline $\mathrm{S} 56$ & 0.9999262613 & S19 & 0.9999320596 & $\mathrm{~S} 71$ & 0.9999380434 \\
\hline $\mathrm{S} 54$ & 0.9999264586 & $\mathrm{~S} 20$ & 0.9999320596 & $\mathrm{~S} 13$ & 0.999938992 \\
\hline S61 & 0.999926567 & $\mathrm{~S} 24$ & 0.9999320596 & S69 & 0.9999398601 \\
\hline $\mathrm{S} 52$ & 0.999927186 & $\mathrm{~S} 25$ & 0.9999320596 & $\mathrm{~S} 15$ & 0.9999398762 \\
\hline $\mathrm{S} 43$ & 0.999927264 & $\mathrm{~S} 26$ & 0.9999320596 & $\mathrm{~S} 42$ & 0.9999398762 \\
\hline $\mathrm{S} 6$ & 0.9999272835 & $\mathrm{~S} 27$ & 0.9999320596 & S74 & 0.9999407143 \\
\hline S5 & 0.9999282594 & $\mathrm{~S} 29$ & 0.9999320596 & $\mathrm{~S} 67$ & 0.9999407381 \\
\hline $\mathrm{S} 8$ & 0.9999282594 & $\mathrm{~S} 31$ & 0.9999320596 & S39 & 0.9999407539 \\
\hline $\mathrm{S} 36$ & 0.999928592 & $\mathrm{~S} 32$ & 0.9999320596 & $\mathrm{~S} 40$ & 0.9999407539 \\
\hline S63 & 0.9999301724 & $\mathrm{~S} 34$ & 0.9999320596 & $\mathrm{~S} 41$ & 0.9999407539 \\
\hline $\mathrm{S} 84$ & 0.9999301724 & $\mathrm{~S} 48$ & 0.9999320596 & S60 & 0.9999407539 \\
\hline $\mathrm{S} 2$ & 0.9999301848 & $\mathrm{~S} 49$ & 0.9999320596 & $\mathrm{~S} 1$ & 0.9999416252 \\
\hline $\mathrm{S} 38$ & 0.9999311008 & $\mathrm{~S} 50$ & 0.9999320596 & $\mathrm{~S} 14$ & 0.9999416252 \\
\hline S9 & 0.9999311193 & S51 & 0.9999320596 & $\mathrm{~S} 89$ & 0.9999416252 \\
\hline S10 & 0.9999311193 & S59 & 0.9999320596 & $\mathrm{~S} 12$ & 0.9999424669 \\
\hline $\mathrm{S} 21$ & 0.9999311193 & S64 & 0.9999320596 & S57 & 0.99994249 \\
\hline $\mathrm{S} 22$ & 0.9999311193 & S65 & 0.9999320596 & $\mathrm{~S} 3$ & 0.999943128 \\
\hline $\mathrm{S} 33$ & 0.9999311193 & $\mathrm{~S} 66$ & 0.9999320596 & $\mathrm{~S} 4$ & 0.9999456377 \\
\hline $\mathrm{S} 35$ & 0.9999311193 & $\mathrm{~S} 72$ & 0.9999320596 & $\mathrm{~S} 30$ & 0.9999585474 \\
\hline $\mathrm{S} 83$ & 0.9999311193 & $\mathrm{~S} 73$ & 0.9999320596 & & \\
\hline
\end{tabular}


Having all the SE of the binary representation of purine and pyrimidine of

the SARS-CoV sequences, only three culsters have been formed using k-means clustering technique. The cluster-1 contains 21 sequences S68, S78, S88, S71, S13, S69, S15, S42, S74, S67, S39, S40, S41, S60, S1, S14, S89, S12, S57, S3 and S4 having SE centred at 0.999940381147619 . The other 67 sequences belong to the other cluster- 2 whose centre is at 0.999930184068656 . Though these two clusters can be considered same. There is only one cluster-3 which contains only one sequence S30 whose SE is 0.9999585474 (approximately 1) as already mentioned before.

It is worth mentioning that the SE is very much linear in trend for all these purine and pyrimidine distribution among the SARS-CoV2 sequences. This is

215 something is crucial in Coronavirus (SARS-CoV2) unlike other sequences as obtained in previous studies made [35, 36, 37]. The amount of uncertainly is at maximum which says the equally likely occurrence of purine and pyrimidine bases across the sequences among all the SARS-CoV2.

\section{GC, A, T, C and G Density in the SARS-CoV2}

In this section, we shall try to investigate the density of each nucleotides and also the $G C$ content in the SARS-CoV2 sequences. Based on density, the sequences are classified as follows. Here we present entire detail list of percentage of density obtained for the $G C$ content among all the SARS-CoV2 sequences as shown in the Table 4,5 and 6. It is found that the density of $G C$ content is around $37.5 \%$ which says that the SARS-CoV2 sequences are essentially $A T$ rich. That is one purine base nucleotide $(A)$ and one pyrimidine base nucleotide $(T)$ are rich (approximately 30\% $\mathrm{A}$ and $32 \% \mathrm{~T}$ ) in these sequences of SARS$\mathrm{CoV} 2$ and as mentioned in the Shannon entropy subsection the occurrence of purine and pyrimidine bases are equally probable. This is what is significant ${ }_{230}$ speciality of the SARS-CoV2 sequences. 

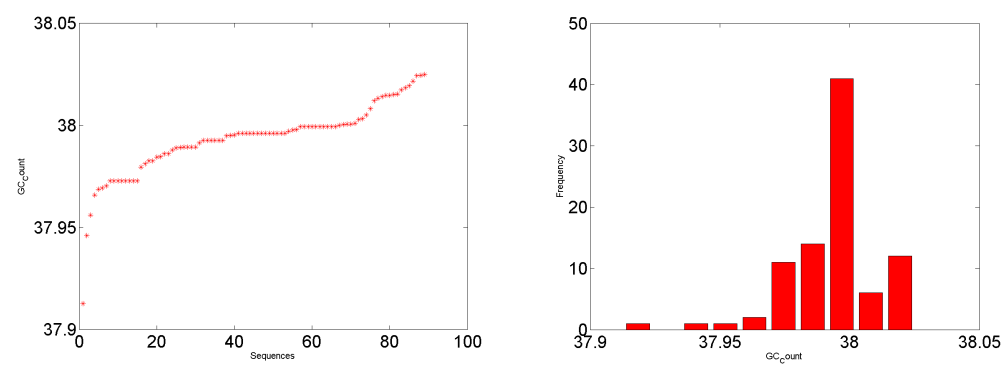

Figure 4: Plot of the GC content density and its corresponding histogram of the SARS-CoV2 sequences.

Based on the GC content density in the SARS-CoV2 sequences, ten different clusters are formed using k-means clustering technique and the following Table 7 describes the sequences and their corresponding clusters where they belong.

There ten clusters (C) having centres at 37.9460, 38.0143, 37.9826, 37.9952, $38.0002,37.9714,37.9888,38.0230,37.9561$ and 37.9128 . The density of all these sequences lies in the interval $(37.91284,38.02505)$. The cluster-10, 9 and 1 contain only one sequence S30, S13 and S60 which has $37.91284 \%, 37.94602 \%$ and $37.95605 \%$ of GC contents respectively. It is noted that the sequence S30 does have the SE 1 as pointed earlier.

Following in the Figures 4, 5,6 and 7, we have given the plot of the percentage of $A, T, C$ and $G$ with their respective histograms.
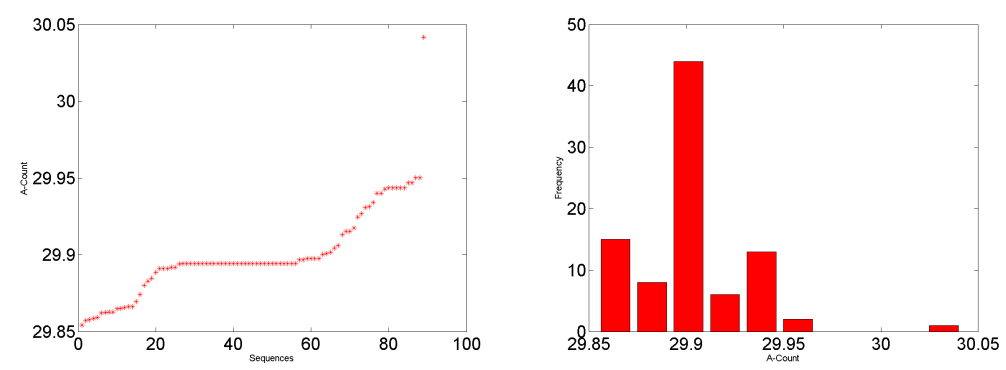

Figure 5: Plot of the $A$ content density and its corresponding histogram of the SARS-CoV2 sequences. 
Table 5: Sequences and their respective percentage of the GC content.

\begin{tabular}{|c|c|c|c|c|c|}
\hline Sequence & $\%$ of $\mathrm{G}, \mathrm{C}$ & $\%$ of $\mathrm{A}$ & $\%$ of $\mathrm{T}$ & $\%$ of $\mathrm{C}$ & $\%$ of $\mathrm{G}$ \\
\hline S1 & 37.972778651 & 29.9434839314 & 32.0837374177 & 18.3660502291 & 19.6067284219 \\
\hline $\mathrm{S} 2$ & 38.0082597455 & 29.8626733371 & 32.1290669174 & 18.36282443 & 19.6454353154 \\
\hline S3 & 37.9795610655 & 29.9313117775 & 32.089127157 & 18.3548333054 & 19.6247277601 \\
\hline $\mathrm{S} 4$ & 37.9889391654 & 29.9245852187 & 32.0864756159 & 18.3475783476 & 19.6413608178 \\
\hline S5 & 37.9860785757 & 29.8942507195 & 32.1163242086 & 18.3789572318 & 19.607121344 \\
\hline S6 & 37.9953145917 & 29.8828647925 & 32.1151271754 & 18.3801874163 & 19.6151271754 \\
\hline $\mathrm{S} 7$ & 37.9994645606 & 29.8942507195 & 32.1062847199 & 18.3789572318 & 19.6205073288 \\
\hline $\mathrm{S} 8$ & 37.9659995984 & 29.8942507195 & 32.1196707048 & 18.3588782545 & 19.607121344 \\
\hline $\mathrm{S} 9$ & 37.9827320795 & 29.8975972157 & 32.1062847199 & 18.3689177431 & 19.6138143364 \\
\hline $\mathrm{S} 10$ & 37.9961180644 & 29.8942507195 & 32.1096312161 & 18.3789572318 & 19.6171608326 \\
\hline S11 & 37.9994645606 & 29.8942507195 & 32.1062847199 & 18.3789572318 & 19.6205073288 \\
\hline $\mathrm{S} 12$ & 37.9703649196 & 29.9428036258 & 32.0868314547 & 18.3597016423 & 19.6106632773 \\
\hline $\mathrm{S} 13$ & 37.9460254824 & 29.9501722235 & 32.1038022941 & 18.3560177909 & 19.5900076915 \\
\hline $\mathrm{S} 14$ & 37.972778651 & 29.9401397853 & 32.0870815637 & 18.362706083 & 19.610072568 \\
\hline $\mathrm{S} 15$ & 37.972778651 & 29.926763201 & 32.0971140019 & 18.3560177909 & 19.6167608601 \\
\hline $\mathrm{S} 16$ & 37.9994645606 & 29.8942507195 & 32.1062847199 & 18.3789572318 & 19.6205073288 \\
\hline $\mathrm{S} 17$ & 37.9994645606 & 29.8942507195 & 32.1062847199 & 18.3789572318 & 19.6205073288 \\
\hline S18 & 37.9994645606 & 29.8942507195 & 32.1062847199 & 18.3789572318 & 19.6205073288 \\
\hline S19 & 37.9961180644 & 29.8942507195 & 32.1096312161 & 18.3756107356 & 19.6205073288 \\
\hline $\mathrm{S} 20$ & 37.9894250719 & 29.8942507195 & 32.1163242086 & 18.3689177431 & 19.6205073288 \\
\hline $\mathrm{S} 21$ & 37.9961180644 & 29.8942507195 & 32.1096312161 & 18.3789572318 & 19.6171608326 \\
\hline $\mathrm{S} 22$ & 37.9994645606 & 29.8909042233 & 32.1096312161 & 18.3789572318 & 19.6205073288 \\
\hline $\mathrm{S} 23$ & 37.9951116617 & 29.9059162286 & 32.0989721097 & 18.381491278 & 19.6136203837 \\
\hline $\mathrm{S} 24$ & 37.9927715682 & 29.8975972157 & 32.1096312161 & 18.3756107356 & 19.6171608326 \\
\hline $\mathrm{S} 25$ & 37.9994645606 & 29.8942507195 & 32.1062847199 & 18.3789572318 & 19.6205073288 \\
\hline $\mathrm{S} 26$ & 37.9994645606 & 29.8942507195 & 32.1062847199 & 18.3789572318 & 19.6205073288 \\
\hline $\mathrm{S} 27$ & 37.9961180644 & 29.8942507195 & 32.1096312161 & 18.3756107356 & 19.6205073288 \\
\hline $\mathrm{S} 28$ & 38.0051561925 & 29.8623899287 & 32.1291057019 & 18.3848394549 & 19.6203167375 \\
\hline $\mathrm{S} 29$ & 37.9894250719 & 29.8975972157 & 32.1129777123 & 18.3722642393 & 19.6171608326 \\
\hline
\end{tabular}


Table 6: Sequences and their respective percentage of the GC content.

\begin{tabular}{|c|c|c|c|c|c|}
\hline Sequence & $\%$ of $\mathrm{G}, \mathrm{C}$ & $\%$ of $\mathrm{A}$ & $\%$ of $\mathrm{T}$ & $\%$ of $\mathrm{C}$ & $\%$ of $\mathrm{G}$ \\
\hline $\mathrm{S} 30$ & 37.912840207 & 30.0417431959 & 32.0454165971 & 18.3336116213 & 19.5792285857 \\
\hline S31 & 37.9994645606 & 29.8942507195 & 32.1062847199 & 18.3789572318 & 19.6205073288 \\
\hline S32 & 37.9961180644 & 29.8942507195 & 32.1096312161 & 18.3756107356 & 19.6205073288 \\
\hline S33 & 37.9927715682 & 29.8942507195 & 32.1129777123 & 18.3756107356 & 19.6171608326 \\
\hline S34 & 37.9894250719 & 29.8942507195 & 32.1163242086 & 18.3689177431 & 19.6205073288 \\
\hline $\mathrm{S} 35$ & 37.9927715682 & 29.8942507195 & 32.1129777123 & 18.3756107356 & 19.6171608326 \\
\hline S36 & 38.0121268969 & 29.8649961475 & 32.1228769555 & 18.374593816 & 19.637533081 \\
\hline $\mathrm{S} 37$ & 38.0183559992 & 29.8619950425 & 32.1196489583 & 18.389495545 & 19.6288604542 \\
\hline $\mathrm{S} 38$ & 37.9978579557 & 29.8848651181 & 32.1172769262 & 18.3713769329 & 19.6264810228 \\
\hline S39 & 37.972778651 & 29.9434839314 & 32.0837374177 & 18.3693943751 & 19.6033842758 \\
\hline $\mathrm{S} 40$ & 37.972778651 & 29.9434839314 & 32.0837374177 & 18.3693943751 & 19.6033842758 \\
\hline $\mathrm{S} 41$ & 37.972778651 & 29.9434839314 & 32.0837374177 & 18.3693943751 & 19.6033842758 \\
\hline $\mathrm{S} 42$ & 37.972778651 & 29.9401397853 & 32.0870815637 & 18.3693943751 & 19.6033842758 \\
\hline $\mathrm{S} 43$ & 38.0004016602 & 29.880171375 & 32.1194269648 & 18.3826482796 & 19.6177533806 \\
\hline S44 & 37.9980596166 & 29.8885952293 & 32.1133451541 & 18.3700779499 & 19.6279816667 \\
\hline $\mathrm{S} 45$ & 37.9860785757 & 29.9042902082 & 32.1096312161 & 18.3722642393 & 19.6138143364 \\
\hline S46 & 38.0132981389 & 29.8740352167 & 32.1126666444 & 18.3935313575 & 19.6197667814 \\
\hline S47 & 38.0140755812 & 29.865581535 & 32.1203428838 & 18.3983189353 & 19.6157566459 \\
\hline $\mathrm{S} 48$ & 37.9961180644 & 29.8942507195 & 32.1096312161 & 18.3756107356 & 19.6205073288 \\
\hline $\mathrm{S} 49$ & 37.9927715682 & 29.9009437119 & 32.1062847199 & 18.3789572318 & 19.6138143364 \\
\hline $\mathrm{S} 50$ & 38.0028110568 & 29.8909042233 & 32.1062847199 & 18.3789572318 & 19.623853825 \\
\hline S51 & 37.9994645606 & 29.8942507195 & 32.1062847199 & 18.3789572318 & 19.6205073288 \\
\hline $\mathrm{S} 52$ & 38.0174146015 & 29.8693904889 & 32.1131949096 & 18.3891493637 & 19.6282652378 \\
\hline $\mathrm{S} 53$ & 38.0010707355 & 29.9002877602 & 32.0986415044 & 18.3764973566 & 19.6245733788 \\
\hline $\mathrm{S} 54$ & 38.0195229949 & 29.8648150012 & 32.115662004 & 18.3891852001 & 19.6303377948 \\
\hline S55 & 38.0147304988 & 29.8627385336 & 32.1225309675 & 18.3829929695 & 19.6317375293 \\
\hline $\mathrm{S} 56$ & 38.0147304988 & 29.8660863743 & 32.1191831269 & 18.3863408102 & 19.6283896887 \\
\hline $\mathrm{S} 57$ & 37.9694345049 & 29.9501722235 & 32.0803932716 & 18.3660502291 & 19.6033842758 \\
\hline $\mathrm{S} 58$ & 38.0032152187 & 29.9015339273 & 32.095250854 & 18.3870319512 & 19.6161832675 \\
\hline S59 & 37.9961180644 & 29.8975972157 & 32.1062847199 & 18.3789572318 & 19.6171608326 \\
\hline S60 & 37.9560579206 & 29.9468280775 & 32.0971140019 & 18.3560177909 & 19.6000401298 \\
\hline
\end{tabular}


Table 7: Sequences and their respective percentage of the GC content.

\begin{tabular}{|c|c|c|c|c|c|}
\hline Sequence & $\%$ of $\mathrm{G}, \mathrm{C}$ & $\%$ of $\mathrm{A}$ & $\%$ of $\mathrm{T}$ & $\%$ of $\mathrm{C}$ & $\%$ of $\mathrm{G}$ \\
\hline S61 & 38.0216538732 & 29.8662554889 & 32.1120906379 & 18.3923842725 & 19.6292696008 \\
\hline $\mathrm{S} 62$ & 37.9999330634 & 29.8939054185 & 32.1061615181 & 18.3774557381 & 19.6224773252 \\
\hline $\mathrm{S} 63$ & 37.9894250719 & 29.8909042233 & 32.1163242086 & 18.3722642393 & 19.6171608326 \\
\hline S64 & 37.9961180644 & 29.8942507195 & 32.1096312161 & 18.3756107356 & 19.6205073288 \\
\hline S65 & 37.9927715682 & 29.8942507195 & 32.1129777123 & 18.3722642393 & 19.6205073288 \\
\hline S66 & 37.9961180644 & 29.8942507195 & 32.1096312161 & 18.3756107356 & 19.6205073288 \\
\hline $\mathrm{S} 67$ & 37.9845479782 & 29.9307669153 & 32.0846851065 & 18.3685073079 & 19.6160406703 \\
\hline S68 & 37.9892940783 & 29.9130143861 & 32.0976915356 & 18.3740381398 & 19.6152559384 \\
\hline S69 & 37.9812033847 & 29.9341115087 & 32.0846851065 & 18.3718519014 & 19.6093514833 \\
\hline S70 & 37.9948465683 & 29.8965967272 & 32.1085567045 & 18.3783422013 & 19.616504367 \\
\hline S71 & 37.9972565158 & 29.917360902 & 32.0853825822 & 18.3779985948 & 19.619257921 \\
\hline $\mathrm{S} 72$ & 37.9961180644 & 29.8942507195 & 32.1096312161 & 18.3756107356 & 19.6205073288 \\
\hline $\mathrm{S} 73$ & 37.9961180644 & 29.8942507195 & 32.1096312161 & 18.3756107356 & 19.6205073288 \\
\hline $\mathrm{S} 74$ & 37.968755227 & 29.94681029 & 32.084434483 & 18.3688488944 & 19.5999063326 \\
\hline $\mathrm{S} 75$ & 38.0242529814 & 29.8572959936 & 32.1184510251 & 18.3940774487 & 19.6301755326 \\
\hline S76 & 38.025055269 & 29.8586454077 & 32.1162993234 & 18.3928451799 & 19.6322100891 \\
\hline $\mathrm{S} 77$ & 38.0245838497 & 29.8589945406 & 32.1164216097 & 18.3943463844 & 19.6302374653 \\
\hline $\mathrm{S} 78$ & 37.9880231508 & 29.9153591382 & 32.096617711 & 18.3734234385 & 19.6145997123 \\
\hline $\mathrm{S} 79$ & 38.0150880134 & 29.8541492037 & 32.1307627829 & 18.383906119 & 19.6311818944 \\
\hline $\mathrm{S} 80$ & 37.9915001841 & 29.8965967272 & 32.1119030887 & 18.374995817 & 19.616504367 \\
\hline $\mathrm{S} 81$ & 38.0007362538 & 29.8919045547 & 32.1073591915 & 18.3795723035 & 19.6211639503 \\
\hline $\mathrm{S} 82$ & 38.0007362538 & 29.8919045547 & 32.1073591915 & 18.3795723035 & 19.6211639503 \\
\hline $\mathrm{S} 83$ & 37.9927715682 & 29.8942507195 & 32.1129777123 & 18.3756107356 & 19.6171608326 \\
\hline S84 & 37.9961180644 & 29.8942507195 & 32.1096312161 & 18.382303728 & 19.6138143364 \\
\hline $\mathrm{S} 85$ & 37.9827320795 & 29.8942507195 & 32.0962452312 & 18.3655712469 & 19.6171608326 \\
\hline $\mathrm{S} 86$ & 38.0152825256 & 29.857899323 & 32.1268181514 & 18.3792479389 & 19.6360345868 \\
\hline S87 & 37.9961180644 & 29.8942507195 & 32.1096312161 & 18.3756107356 & 19.6205073288 \\
\hline S 88 & 37.9846776622 & 29.9153591382 & 32.0999631996 & 18.3700779499 & 19.6145997123 \\
\hline S89 & 37.972778651 & 29.9434839314 & 32.0837374177 & 18.3660502291 & 19.6067284219 \\
\hline
\end{tabular}


Table 8: Sequences and their respective percentage of the GC content and clusters where they belong.

\begin{tabular}{|c|c|c|c|c|c|c|c|c|}
\hline Seq & $\%$ of GC & C & Seq & $\%$ of $\mathrm{GC}$ & C & Seq & $\%$ of $\mathrm{GC}$ & $\mathrm{C}$ \\
\hline $\mathrm{S} 30$ & 37.912840207 & 10 & $\mathrm{~S} 24$ & 37.9927715682 & 4 & $\mathrm{~S} 22$ & 37.9994645606 & 5 \\
\hline S13 & 37.9460254824 & 1 & S33 & 37.9927715682 & 4 & $\mathrm{~S} 25$ & 37.9994645606 & 5 \\
\hline $\mathrm{S} 60$ & 37.9560579206 & 9 & S35 & 37.9927715682 & 4 & $\mathrm{~S} 26$ & 37.9994645606 & 5 \\
\hline S8 & 37.9659995984 & 6 & S49 & 37.9927715682 & 4 & S31 & 37.9994645606 & 5 \\
\hline S74 & 37.968755227 & 6 & S65 & 37.9927715682 & 4 & $\mathrm{~S} 51$ & 37.9994645606 & 5 \\
\hline $\mathrm{S} 57$ & 37.9694345049 & 6 & $\mathrm{~S} 83$ & 37.9927715682 & 4 & $\mathrm{~S} 62$ & 37.9999330634 & 5 \\
\hline S12 & 37.9703649196 & 6 & S70 & 37.9948465683 & 4 & $\mathrm{~S} 43$ & 38.0004016602 & 5 \\
\hline S1 & 37.972778651 & 6 & $\mathrm{~S} 23$ & 37.9951116617 & 4 & S81 & 38.0007362538 & 5 \\
\hline S14 & 37.972778651 & 6 & S6 & 37.9953145917 & 4 & S82 & 38.0007362538 & 5 \\
\hline $\mathrm{S} 15$ & 37.972778651 & 6 & S10 & 37.9961180644 & 4 & $\mathrm{~S} 53$ & 38.0010707355 & 5 \\
\hline S39 & 37.972778651 & 6 & S19 & 37.9961180644 & 4 & $\mathrm{~S} 50$ & 38.0028110568 & 5 \\
\hline $\mathrm{S} 40$ & 37.972778651 & 6 & $\mathrm{~S} 21$ & 37.9961180644 & 4 & $\mathrm{~S} 58$ & 38.0032152187 & 5 \\
\hline S41 & 37.972778651 & 6 & $\mathrm{~S} 27$ & 37.9961180644 & 4 & $\mathrm{~S} 28$ & 38.0051561925 & 5 \\
\hline S42 & 37.972778651 & 6 & S32 & 37.9961180644 & 4 & $\mathrm{~S} 2$ & 38.0082597455 & 2 \\
\hline S89 & 37.972778651 & 6 & $\mathrm{~S} 48$ & 37.9961180644 & 4 & $\mathrm{~S} 36$ & 38.0121268969 & 2 \\
\hline S3 & 37.9795610655 & 3 & $\mathrm{~S} 59$ & 37.9961180644 & 4 & $\mathrm{~S} 46$ & 38.0132981389 & 2 \\
\hline S69 & 37.9812033847 & 3 & $\mathrm{~S} 64$ & 37.9961180644 & 4 & $\mathrm{~S} 47$ & 38.0140755812 & 2 \\
\hline S9 & 37.9827320795 & 3 & S66 & 37.9961180644 & 4 & $\mathrm{~S} 55$ & 38.0147304988 & 2 \\
\hline S85 & 37.9827320795 & 3 & $\mathrm{~S} 72$ & 37.9961180644 & 4 & $\mathrm{~S} 56$ & 38.0147304988 & 2 \\
\hline $\mathrm{S} 67$ & 37.9845479782 & 3 & $\mathrm{~S} 73$ & 37.9961180644 & 4 & $\mathrm{~S} 79$ & 38.0150880134 & 2 \\
\hline S88 & 37.9846776622 & 3 & $\mathrm{~S} 84$ & 37.9961180644 & 4 & $\mathrm{~S} 86$ & 38.0152825256 & 2 \\
\hline S5 & 37.9860785757 & 7 & $\mathrm{~S} 87$ & 37.9961180644 & 4 & $\mathrm{~S} 52$ & 38.0174146015 & 2 \\
\hline $\mathrm{S} 45$ & 37.9860785757 & 7 & $\mathrm{~S} 71$ & 37.9972565158 & 4 & $\mathrm{~S} 37$ & 38.0183559992 & 2 \\
\hline $\mathrm{S} 78$ & 37.9880231508 & 7 & S38 & 37.9978579557 & 5 & $\mathrm{~S} 54$ & 38.0195229949 & 8 \\
\hline S4 & 37.9889391654 & 7 & $\mathrm{~S} 44$ & 37.9980596166 & 5 & S61 & 38.0216538732 & 8 \\
\hline S68 & 37.9892940783 & 7 & $\mathrm{~S} 7$ & 37.9994645606 & 5 & $\mathrm{~S} 75$ & 38.0242529814 & 8 \\
\hline $\mathrm{S} 20$ & 37.9894250719 & 7 & $\mathrm{~S} 11$ & 37.9994645606 & 5 & $\mathrm{~S} 77$ & 38.0245838497 & 8 \\
\hline $\mathrm{S} 29$ & 37.9894250719 & 7 & S16 & 37.9994645606 & 5 & $\mathrm{~S} 76$ & 38.025055269 & 8 \\
\hline $\mathrm{S} 34$ & 37.9894250719 & 7 & $\mathrm{~S} 17$ & 37.9994645606 & 5 & & & \\
\hline S63 & 37.9894250719 & 7 & $\mathrm{~S} 18$ & 37.9994645606 & 5 & & & \\
\hline $\mathrm{S} 80$ & 37.9915001841 & 7 & & & & & & \\
\hline
\end{tabular}

Table 9: Sequences and their respective perceatlage of the GC content and clusters where they belong. 

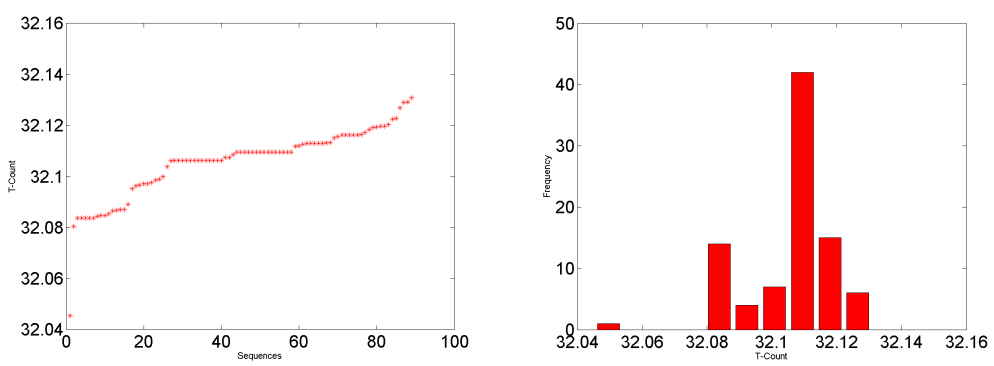

Figure 6: Plot of the $T$ content density and its corresponding histogram of the SARS-CoV2 sequences.
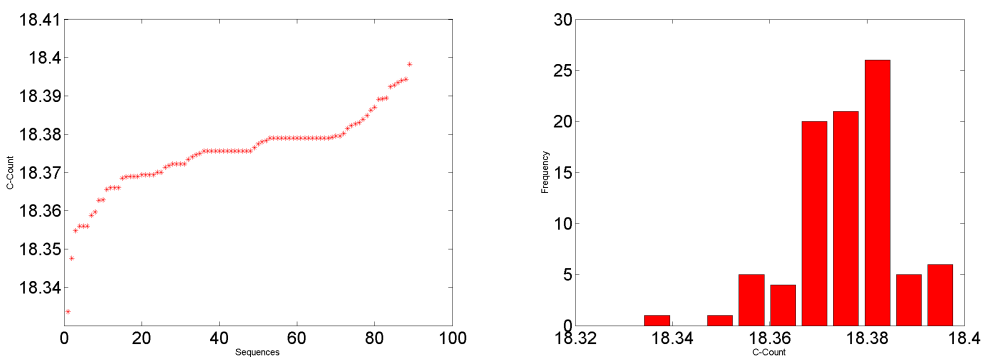

Figure 7: Plot of the $C$ content density and its corresponding histogram of the SARS-CoV2 sequences.
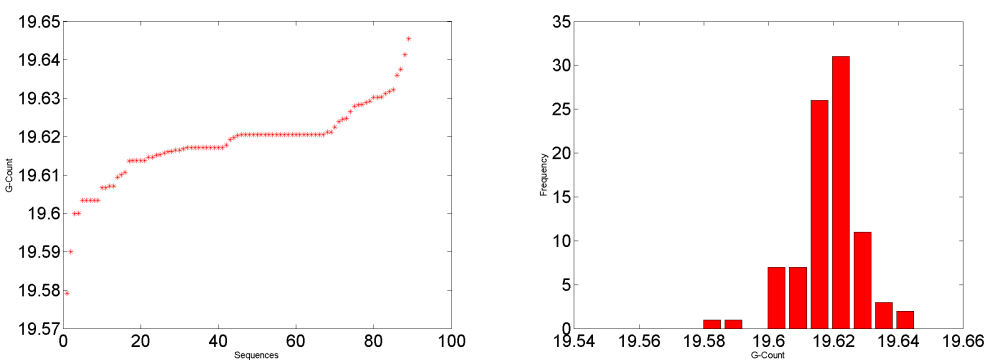

Figure 8: Plot of the $G$ content density and its corresponding histogram of the SARS-CoV2 sequences.

In the following Table 8 the percentage of density in the SARS-CoV2 se- 
quences of $A, T, C$ and $G$ are given explicitly.

Table 10: Sequences and their respective percentage of the A, T, C and G contents.

\begin{tabular}{|c|c|c|c|c|c|c|c|c|c|c|c|c|c|c|}
\hline Seq & \% A & $\% \mathrm{~T}$ & $\% \mathrm{C}$ & $\% \mathrm{G}$ & Seq & $\% \mathrm{~A}$ & $\% \mathrm{~T}$ & $\% \mathrm{C}$ & $\% \mathrm{G}$ & Seq & \% A & $\% \mathrm{~T}$ & $\% \mathrm{C}$ & $\% \mathrm{G}$ \\
\hline S1 & 29.94 & 32.08 & 18.37 & 19.61 & S31 & 29.89 & 32.11 & 18.38 & 19.62 & S61 & 29.87 & 32.11 & 18.39 & 19.63 \\
\hline S2 & 29.86 & 32.13 & 18.36 & 19.65 & S32 & 29.89 & 32.11 & 18.38 & 19.62 & S62 & 29.89 & 32.11 & 18.38 & 19.62 \\
\hline S3 & 29.93 & 32.09 & 18.35 & 19.62 & S33 & 29.89 & 32.11 & 18.38 & 19.62 & S63 & 29.89 & 32.12 & 18.37 & 19.62 \\
\hline $\mathrm{S} 4$ & 29.92 & 32.09 & 18.35 & 19.64 & S34 & 29.89 & 32.12 & 18.37 & 19.62 & S64 & 29.89 & 32.11 & 18.38 & 19.62 \\
\hline S5 & 29.89 & 32.12 & 18.38 & 19.61 & S35 & 29.89 & 32.11 & 18.38 & 19.62 & S65 & 29.89 & 32.11 & 18.37 & 19.62 \\
\hline S6 & 29.88 & 32.12 & 18.38 & 19.62 & S36 & 29.86 & 32.12 & 18.37 & 19.64 & S66 & 29.89 & 32.11 & 18.38 & 19.62 \\
\hline S7 & 29.89 & 32.11 & 18.38 & 19.62 & S37 & 29.86 & 32.12 & 18.39 & 19.63 & S67 & 29.93 & 32.08 & 18.37 & 19.62 \\
\hline S8 & 29.89 & 32.12 & 18.36 & 19.61 & S38 & 29.88 & 32.12 & 18.37 & 19.63 & S68 & 29.91 & 32.10 & 18.37 & 19.62 \\
\hline s9 & 29.90 & 32.11 & 18.37 & 19.61 & S39 & 29.94 & 32.08 & 18.37 & 19.60 & S69 & 29.93 & 32.08 & 18.37 & 19.61 \\
\hline S10 & 29.89 & 32.11 & 18.38 & 19.62 & $\mathrm{~S} 40$ & 29.94 & 32.08 & 18.37 & 19.60 & S70 & 29.90 & 32.11 & 18.38 & 19.62 \\
\hline S11 & 29.89 & 32.11 & 18.38 & 19.62 & $\mathrm{~S} 41$ & 29.94 & 32.08 & 18.37 & 19.60 & S71 & 29.92 & 32.09 & 18.38 & 19.62 \\
\hline $\mathrm{S} 12$ & 29.94 & 32.09 & 18.36 & 19.61 & $\mathrm{~S} 42$ & 29.94 & 32.09 & 18.37 & 19.60 & S72 & 29.89 & 32.11 & 18.38 & 19.62 \\
\hline $\mathrm{S} 13$ & 29.95 & 32.10 & 18.36 & 19.59 & $\mathrm{~S} 43$ & 29.88 & 32.12 & 18.38 & 19.62 & S73 & 29.89 & 32.11 & 18.38 & 19.62 \\
\hline S14 & 29.94 & 32.09 & 18.36 & 19.61 & S44 & 29.89 & 32.11 & 18.37 & 19.63 & S74 & 29.95 & 32.08 & 18.37 & 19.60 \\
\hline S15 & 29.93 & 32.10 & 18.36 & 19.62 & S45 & 29.90 & 32.11 & 18.37 & 19.61 & S75 & 29.86 & 32.12 & 18.39 & 19.63 \\
\hline S16 & 29.89 & 32.11 & 18.38 & 19.62 & S46 & 29.87 & 32.11 & 18.39 & 19.62 & S76 & 29.86 & 32.12 & 18.39 & 19.63 \\
\hline S17 & 29.89 & 32.11 & 18.38 & 19.62 & $\mathrm{~S} 47$ & 29.87 & 32.12 & 18.40 & 19.62 & S77 & 29.86 & 32.12 & 18.39 & 19.63 \\
\hline $\mathrm{S} 18$ & 29.89 & 32.11 & 18.38 & 19.62 & $\mathrm{~S} 48$ & 29.89 & 32.11 & 18.38 & 19.62 & S78 & 29.92 & 32.10 & 18.37 & 19.61 \\
\hline $\mathrm{S} 19$ & 29.89 & 32.11 & 18.38 & 19.62 & S49 & 29.90 & 32.11 & 18.38 & 19.61 & S79 & 29.85 & 32.13 & 18.38 & 19.63 \\
\hline S2O & 29.89 & 32.12 & 18.37 & 19.62 & S50 & 29.89 & 32.11 & 18.38 & 19.62 & S80 & 29.90 & 32.11 & 18.37 & 19.62 \\
\hline S21 & 29.89 & 32.11 & 18.38 & 19.62 & S51 & 29.89 & 32.11 & 18.38 & 19.62 & S81 & 29.89 & 32.11 & 18.38 & 19.62 \\
\hline S22 & 29.89 & 32.11 & 18.38 & 19.62 & S52 & 29.87 & 32.11 & 18.39 & 19.63 & S82 & 29.89 & 32.11 & 18.38 & 19.62 \\
\hline S23 & 29.91 & 32.10 & 18.38 & 19.61 & S53 & 29.90 & 32.10 & 18.38 & 19.62 & S83 & 29.89 & 32.11 & 18.38 & 19.62 \\
\hline S24 & 29.90 & 32.11 & 18.38 & 19.62 & S54 & 29.86 & 32.12 & 18.39 & 19.63 & S84 & 29.89 & 32.11 & 18.38 & 19.61 \\
\hline S25 & 29.89 & 32.11 & 18.38 & 19.62 & S55 & 29.86 & 32.12 & 18.38 & 19.63 & S85 & 29.89 & 32.10 & 18.37 & 19.62 \\
\hline S26 & 29.89 & 32.11 & 18.38 & 19.62 & S56 & 29.87 & 32.12 & 18.39 & 19.63 & S86 & 29.86 & 32.13 & 18.38 & 19.64 \\
\hline S27 & 29.89 & 32.11 & 18.38 & 19.62 & S57 & 29.95 & 32.08 & 18.37 & 19.60 & S87 & 29.89 & 32.11 & 18.38 & 19.62 \\
\hline S28 & 29.86 & 32.13 & 18.38 & 19.62 & S58 & 29.90 & 32.10 & 18.39 & 19.62 & S 88 & 29.92 & 32.10 & 18.37 & 19.61 \\
\hline S29 & 29.90 & 32.11 & 18.37 & 19.62 & S59 & 29.90 & 32.11 & 18.38 & 19.62 & S89 & 29.94 & 32.08 & 18.37 & 19.61 \\
\hline S30 & 30.04 & 32.05 & 18.33 & 19.58 & S60 & 29.95 & 32.10 & 18.36 & 19.60 & & & & & \\
\hline
\end{tabular}

In the above Table 8 , it is observed that the intervals where the density of ${ }_{245} \mathrm{~A}, \mathrm{~T}, \mathrm{C}$ and $\mathrm{G}$ lie are $(29.85,30.04),(32.05,32.13),(18.33,18.40)$ and $(19.58$, 19.65) respectively. That is the approximately A, T, C and G are spread over these SARS-CoV2 sequences in 30\%, 32\%, $18 \%$ and $19 \%$ respectively. It is noted that the density of $A$ and $T$ are significantly rich as seen here. This illustrates the density of purine and pyrimidine bases are kept almost same as confirmed in SE previously.

All the sequences of SARS-CoV2 sequences are clustered into different clusters. The centre of each cluster in all the four cases (A, T, C and G) is differed 
by 0.01 distance. The sequence $S 79$ has the least percentage $(29.85 \%)$ of the

Following we are yet to discover the purine-pyrimidine closeness of the SARSnucleotide base $A$ where as the sequence S30 has least percentage of $T, C$ and $G$ densities. It is also observed that S79, S47 and S2 have the highest percentages (32.13\%) of $\mathrm{T}$ density, $18.40 \%$ of $\mathrm{C}$ density and $19.65 \%$ of $\mathrm{G}$ density respectively. the sequences into some clusters based on the closeness of purine-pyrimidine sequences similarity.

\subsection{Hamming Distance of the SARS-COV2}

The similarity analysis of the SARS-CoV2 sequences have been measured by calculating the distance between the vectors of binary strings encoded on the basis of purines and pyrimidines nucleotide bases as mentioned earlier. There are several computing methods for measuring the distance between multidimensional vectors, such as Hamming Distance, Euclidean distance, Elastic-matching distance, Jeffrey's and Matusita distance, Manhattan distance andMinkowski norm. Reportedly, these methods have little effect on the similarity of vectors 38. The Hamming Distance (HD) between two binary strings is the number of bits in which they differ [39, 40, 41]. Since length of the different $S A R S-C o V 2$ genome usually differ by some bases and hence a special care has been taken into consideration. Suppose there are two $S A R S-\operatorname{CoV} 2 S_{x}^{1}$ and $S_{y}^{2}$ of length $x$ and $y$ respectively $(x>y)$, then

$$
H D\left(S_{x}^{1}, S_{y}^{2}\right)=h d\left(S_{y}^{1}, S_{y}^{2}\right)
$$

For example, take two binary sequences $S_{x}=101011$ and $S_{m}=0010$, of minimum length 4 , from left to right alignment of these two sequences, we find the hamming distances are $h d(101011,0010)=1$, Finding the minimum hamming distance of the two binary sequences says about the maximum similarity ${ }_{280}$ of two sequences over the distribution of purines and pyrimidines. The minimum value of $H D=0$ when the pattern of length $\min (x, y)$ of two binary 
sequences of are exactly identical i.e. similar distribution of purines and pyrimidines over the $S A R S-C o V 2$ of the two sequences and the maximum value of $H D=\min (n, m)$ when the pattern of length $\min (n, m)$ of two binary sequences of $S A R S-C o V 2$ are exactly opposite i.e. completely dissimilar distribution of purines and pyrimidines over $S A R S-C o V 2$ two sequences.To get the nearness of the $S A R S-C o V 2$ based on their purine-pyrimidine distribution, minimum Hamming distance is deployed.

In order to demonstrate the methodology, the measure of distances (Hamming distance) among the 89 SARS-CoV2 sequences as depicted in the Table 10 are taken into consideration. It is noted that if two virus sequences are having large hamming distance between them then it inferences that these two sequences are unlikely related to each other. From the Figure 9, the following conclusions can be drawn, the SARS-COV2 virus sequences MT044258(S59), MN994468 (S84), NC_045512(S1), . . MN039888(S60) are grouped together as a single cluster as the distance between them is almost negligible and it indicates the closeness among them. Also it should be noted that the sequences MT152824(S38), MN996531(S76), MT012098(S36) and MT975262(S86) are closely related to each other and therefore is treated as a cluster. Similarly the sequences MT163719(S13), MT007544(S74), MT03988(S62), MT188341(S2), MT188339(S3), MT188340 (S4), MN123290(S45), MT039873(S61), MT159721(S23) and MN072688(S54) depicts similar Hamming distances and are grouped together as shown in Figure 9. This closeness(nearness) among the SARS-CoV2 genomes would enable future such genomes or other Blasted results to get into the clusters quantitatively instead of just by sequential similarity.

\section{Conclusions and Summary}

It is needless to mention that the novel coronavirus has led to a public health emergency of world concern according to WHO (https : //www.who.int/). One of the major reasons for such a global threat is due to the lack of quantitative as well as qualitative knowledge about this novel virus including its genomic and 
proteomic levels.

In this article, an attempt has been made to clarify the quantitative nature of the SARS-CoV complete sequences. This present study also reveals the closeness among the 89 complete sequences in the purine-pyrimidine level descriptions through phylogenetic analysis. Also one of the major fact of the 89 SARS$\mathrm{CoV}$ sequences have been exposed that the purine and pyrimidine distribution among all these genes are evenly-equally spatially placed though the $G C$ content is significantly low as described in the result. We believe this quantitative piece of information would enable researcher to comprehend the genomic description of the SARS-CoV sequences better and would atleast help passively in ensuring proper healthcare facility against this massive global emergency. In our future endeavour, we wish to understand the proteins of the SARS-CoV2.

\section{Authors Contributions and Conflicts of Interest:}

The author SH has formulated and carried out the study with RKR and VS. 325 The authors $\mathrm{SH}$ and RKR analyse the study and written the manuscript and finally all the three authors checked and approved the manuscript. The authors declare that there is no conflicts of interest. 


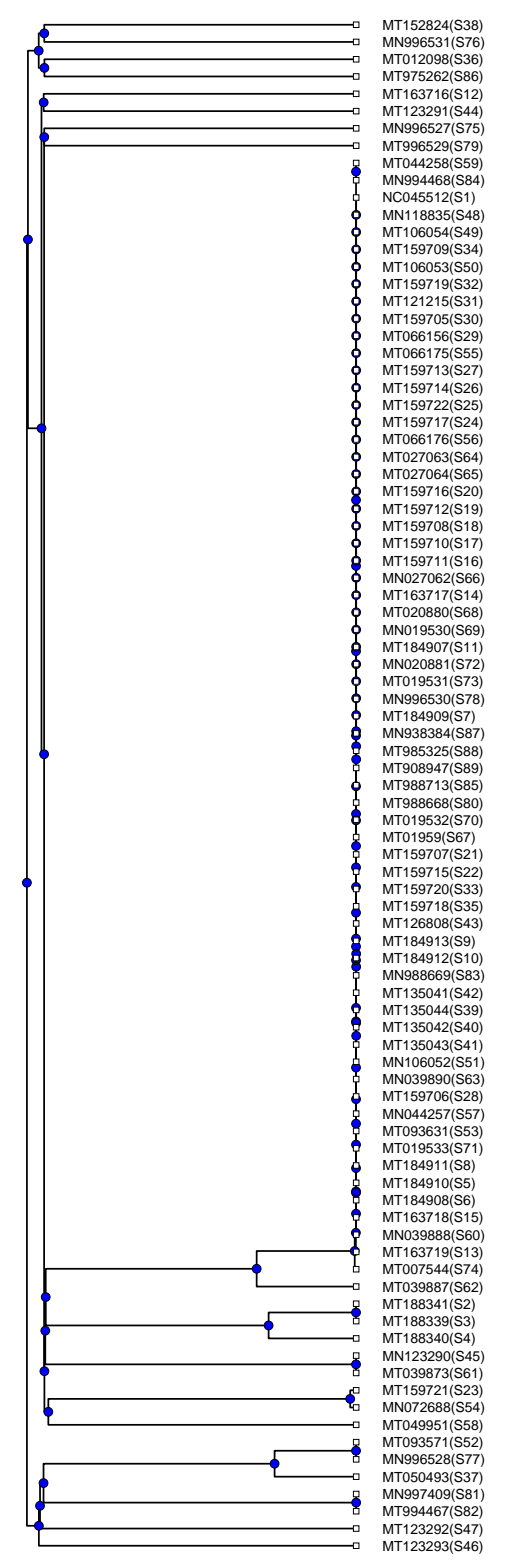

Figure 9: Phylogenetic tree of SARS-CoV2 sequences based on the distribution of purines and pyrimidines (cluster dendrogram using UPGMA distance method) 
Table 11: Hamming distance Matrix of the SARS-CoV2 sequences

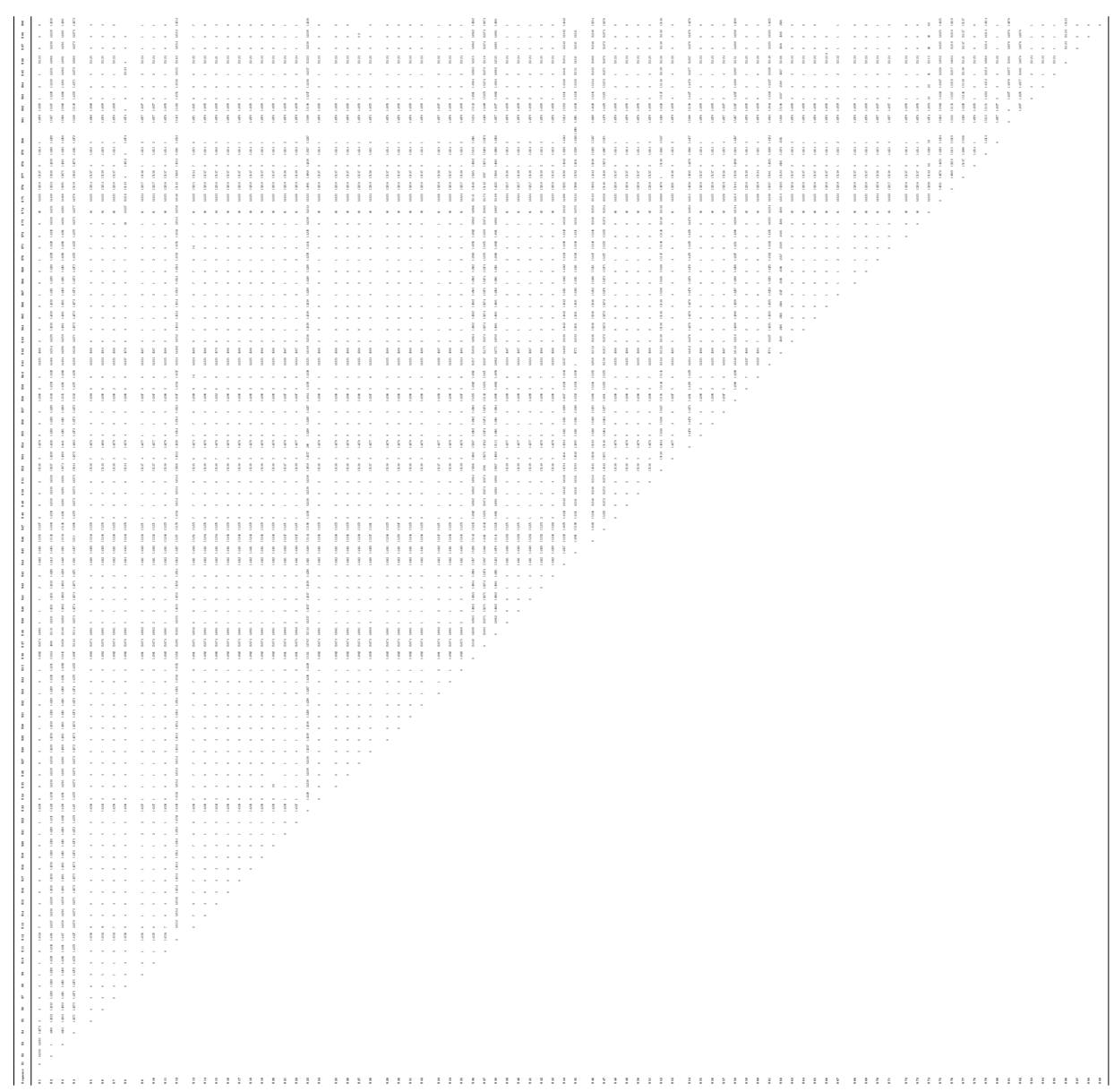

\section{References}

[1] K. V. Holmes, Sars-associated coronavirus, New England Journal of Medicine 348 (20) (2003) 1948-1951.

[2] L. van der Hoek, K. Pyrc, M. F. Jebbink, W. Vermeulen-Oost, R. J. Berkhout, K. C. Wolthers, P. M. Wertheim-van Dillen, J. Kaandorp, J. Spaargaren, B. Berkhout, Identification of a new human coronavirus, Nature medicine 10 (4) (2004) 368-373. 
[3] M. Lipsitch, D. L. Swerdlow, L. Finelli, Defining the epidemiology of covid19 - studies needed, New England Journal of Medicine (2020).

[4] A. S. Fauci, H. C. Lane, R. R. Redfield, Covid-19 - navigating the uncharted (2020).

[5] W. Liu, Q. Zhang, J. Chen, R. Xiang, H. Song, S. Shu, L. Chen, L. Liang, J. Zhou, L. You, et al., Detection of covid-19 in children in early january 2020 in wuhan, china, New England Journal of Medicine (2020).

[6] F. Jiang, L. Deng, L. Zhang, Y. Cai, C. W. Cheung, Z. Xia, Review of the clinical characteristics of coronavirus disease 2019 (covid-19), Journal of General Internal Medicine (2020) 1-5.

[7] J. Stebbing, A. Phelan, I. Griffin, C. Tucker, O. Oechsle, D. Smith, P. Richardson, Covid-19: combining antiviral and anti-inflammatory treatments, The Lancet Infectious Diseases (2020).

[8] J. F.-W. Chan, C. C.-Y. Yip, K. K.-W. To, T. H.-C. Tang, S. C.-Y. Wong, K.-H. Leung, A. Y.-F. Fung, A. C.-K. Ng, Z. Zou, H.-W. Tsoi, et al., Improved molecular diagnosis of covid-19 by the novel, highly sensitive and specific covid-19-rdrp/hel real-time reverse transcription-polymerase chain reaction assay validated in vitro and with clinical specimens, Journal of Clinical Microbiology (2020).

[9] C. Sohrabi, Z. Alsafi, N. O'Neill, M. Khan, A. Kerwan, A. Al-Jabir, C. Iosifidis, R. Agha, World health organization declares global emergency: A review of the 2019 novel coronavirus (covid-19), International Journal of Surgery (2020).

[10] M. A. Marra, S. J. Jones, C. R. Astell, R. A. Holt, A. Brooks-Wilson, Y. S. Butterfield, J. Khattra, J. K. Asano, S. A. Barber, S. Y. Chan, et al., The genome sequence of the sars-associated coronavirus, Science 300 (5624) (2003) 1399-1404. 
[11] P. Sun, X. Lu, C. Xu, W. Sun, B. Pan, Understanding of covid-19 based on current evidence, Journal of Medical Virology (2020).

[12] S. Zhang, M. Y. Diao, L. Duan, Z. Lin, D. Chen, The novel coronavirus (sars-cov-2) infections in china: prevention, control and challenges, Intensive Care Medicine (2020) 1-3.

[13] C. Ceraolo, F. M. Giorgi, Genomic variance of the 2019-ncov coronavirus, Journal of Medical Virology (2020).

[14] G. Kampf, D. Todt, S. Pfaender, E. Steinmann, Persistence of coronaviruses on inanimate surfaces and its inactivation with biocidal agents, Journal of Hospital Infection (2020).

[15] S. Khan, A. Ali, R. Siddique, G. Nabi, Novel coronavirus is putting the whole world on alert, Journal of Hospital Infection 104 (3) (2020) 252-253.

[16] J. Xu, S. Zhao, T. Teng, A. E. Abdalla, W. Zhu, L. Xie, Y. Wang, X. Guo, Systematic comparison of two animal-to-human transmitted human coronaviruses: Sars-cov-2 and sars-cov, Viruses 12 (2) (2020) 244.

[17] W.-B. Yu, G.-D. Tang, L. Zhang, R. T. Corlett, Decoding the evolution and transmissions of the novel pneumonia coronavirus (sars-cov-2) using whole genomic data, ChinaXiv 202002 (2020) v2.

[18] C. Cattani, G. Pierro, On the fractal geometry of dna by the binary image analysis, Bulletin of Mathematical Biology 75 (9) (2013) 1544-1570.

[19] C. Cattani, Fractals and hidden symmetries in dna, Mathematical problems in engineering 2010 (2010).

[20] S. S. Hassan, P. P. Choudhury, B. Daya Sagar, S. Chakraborty, R. Guha, A. Goswami, Quantitative description of genomic evolution of olfactory receptors, Asian-European Journal of Mathematics 8 (03) (2015) 1550043. 
[21] R. K. Rout, P. Pal Choudhury, S. P. Maity, B. Daya Sagar, S. S. Hassan, Fractal and mathematical morphology in intricate comparison between tertiary protein structures, Computer Methods in Biomechanics and Biomedical Engineering: Imaging \& Visualization 6 (2) (2018) 192-203.

[22] C. L. Berthelsen, J. A. Glazier, M. H. Skolnick, Global fractal dimension of human dna sequences treated as pseudorandom walks, Physical Review A 45 (12) (1992) 8902.

[23] A. Carbone, G. Castelli, H. E. Stanley, Time-dependent hurst exponent in financial time series, Physica A: Statistical Mechanics and its Applications 344 (1-2) (2004) 267-271.

[24] J. Mielniczuk, P. Wojdyłło, Estimation of hurst exponent revisited, Computational Statistics \& Data Analysis 51 (9) (2007) 4510-4525.

[25] C. E. Shannon, Prediction and entropy of printed english, Bell system technical journal 30 (1) (1951) 50-64.

[26] S. Noorizadeh, E. Shakerzadeh, Shannon entropy as a new measure of aromaticity, shannon aromaticity, Physical Chemistry Chemical Physics 12 (18) (2010) 4742-4749.

[27] Y. Benjamini, T. Speed, Estimation and correction for gc-content bias in high throughput sequencing, Nucleic Acids Res 40 (10) (2011) e72.

[28] D. Risso, K. Schwartz, G. Sherlock, S. Dudoit, Gc-content normalization for rna-seq data, BMC bioinformatics 12 (1) (2011) 480.

[29] N. Galtier, G. Piganeau, D. Mouchiroud, L. Duret, Gc-content evolution in mammalian genomes: the biased gene conversion hypothesis, Genetics 159 (2) (2001) 907-911.

[30] F. Hildebrand, A. Meyer, A. Eyre-Walker, Evidence of selection upon genomic gc-content in bacteria, PLoS genetics 6 (9) (2010). 
[31] S. Dutta, M. Ojha, Relatedness between major taxonomic groups of fungi based on the measurement of dna nucleotide sequence homology, Molecular and General Genetics MGG 114 (3) (1972) 232-240.

[32] T. H. Jukes, Silent nucleotide substitutions and the molecular evolutionary clock, Science 210 (4473) (1980) 973-978.

[33] M. El Naschie, On dimensions of cantor set related systems, Chaos, Solitons \& Fractals 3 (6) (1993) 675-685.

[34] I. S. Baek, Dimensions of the perturbed cantor set, Real Analysis Exchange 19 (1) (1993) 269-273.

[35] J. K. Das, P. P. Choudhury, A. Chaudhuri, S. S. Hassan, P. Basu, Analysis of purines and pyrimidines distribution over mirnas of human, gorilla, chimpanzee, mouse and rat, Scientific reports 8 (1) (2018) 1-19.

[36] R. K. Rout, S. S. Hassan, S. SINDHWANI, H. M. PANDEY, S. Umer, Intelligent classification and analysis of essential genes species using quantitative methods, ACM Transactions on Mulitmedia Computing, Communications, and Applications (TOMM) (2019) TOMM-2019.

[37] J. P. Banerjee, J. K. Das, P. P. Choudhury, S. Mukherjee, S. S. Hassan, P. Basu, The variations of human mirnas and ising like base pairing models, BioRxiv (2018) 319301.

[38] S. Xu, Z. Li, S. Zhang, J. Hu, Primary structure similarity analysis of proteins sequences by a new graphical representation, SAR and QSAR in Environmental Research 25 (10) (2014) 791-803.

[39] Y. ZuGuo, C. GuoYi, Rescaled range and transition matrix analysis of dna sequences, Communications in Theoretical Physics 33 (4) (2000) 673.

[40] R. W. Hamming, Error detecting and error correcting codes, The Bell system technical journal 29 (2) (1950) 147-160. 
[41] M. Norouzi, D. J. Fleet, R. R. Salakhutdinov, Hamming distance metric learning, in: Advances in neural information processing systems, 2012, pp. $1061-1069$. 